\title{
AUTORIDADE PARENTAL: DIREITO DE FAMÍLIA E PRINCÍPIOS CONSTITUCIONAIS
}

\section{PARENTAL AUTHORITY: FAMILY RIGHTS AND CONSTITUTIONAL PRINCIPLES}

\author{
Léia Comar Riva*
}

\section{RESUMO}

O poder familiar quanto à pessoa dos filhos desafiou o tempo; está previsto em quase todos os sistemas jurídicos modernos e é considerado um dos institutos mais importantes do direito privado. O presente estudo objetiva refletir sobre os direitos e deveres dos pais em relação à pessoa dos filhos e às alterações estabelecidas pela Lei $n^{\circ} 13.058 / 2014$, com ênfase nas relações familiares e nos princípios constitucionais. O procedimento metodológico constitui-se de pesquisas bibliográfica e documental fundadas na discussão teórica do material levantado. Após a análise, os dados sugerem, em relação ao exercício do poder familiar, que as mudanças ocorreram muito mais na concepção em torno do instituto do que na letra da lei, e que um dos caminhos possíveis para o tornar mais efetivo é a valorização das autoridades paterna e materna pela família, sociedade em geral e Estado. Quanto às alterações trazidas pela indicada Lei, verificou-se que a extensão das competências é apenas de denominação, pois, ou estavam previstas em leis anteriores e foram reintegradas no atual ordenamento jurídico, ou constam em outras leis vigentes, ou foram decorrência da guarda compartilhada. Verificou-se, ainda, que a edição de lei ordinária que altera outra lei ordinária nem sempre se mostra a melhor solução para regulamentar as questões sociais. Finalmente, no que diz respeito aos princípios constitucionais, foi possível refletir acerca da possibilidade do diálogo entre o direito de família, em geral, e seu instituto do poder familiar, em particular.

\section{PALAVRAS-CHAVE}

Família. Filhos. Mudanças. Princípios constitucionais. Poder familiar.

\begin{abstract}
The family power toward the person of the children has challenged time; it is foreseen in almost all modern legal systems and is considered one of the most important institutes of private law. This study aims to reflect upon the rights and duties of parents to their children and the changes established by Law No. 13.058/2014, with an emphasis on family relations and on constitutional principles. The methodological procedure consists of bibliographic and documentary research based on the theoretical discussion of the collected material. After the analysis, the data suggest, regarding the exercise of parental authority, that changes occurred more in the design around the institute than in the letter of law, and that one of the possible ways to make it more effective is the appreciation of the paternal and maternal authority by the family, society, and state. As to the changes introduced by the indicated Law, it was found that the prorogation of jurisdictions is just nominal, once they

\footnotetext{
* Doutora em Direito Civil (FD-USP - Universidade de São Paulo). Mestre em Ciências (FFCLRP-USP). Especialista em Violência Doméstica contra Crianças e Adolescentes (IP-USP). Professora Efetiva de Direito Civil do Curso de Direito e de Especialização em Direitos Humanos da Universidade Estadual de Mato Grosso do Sul (UEMS, Paranaíba, MS, Brasil), Unidade de Paranaíba-MS. Pesquisadora do Grupo de Estudo e Pesquisa GREDIFAMS. Membroassociado da Academia Brasileira de Direito Civil (ABDC). Associada do Instituto Brasileiro de Direito de Família (IBDFAM).E-mail: lcriva@uems.br
} 
were foreseen in previous laws, being reintegrated in the current juridical order, or are included in other applicable laws, or were a result of joint custody. It is concluded too that the creation of ordinary law which alters another ordinary law is not always the best solution to regulate social issues. Finally, regarding the constitutional principles, it was possible to reflect on the possibility of a dialogue between family law, in general, and its family power regime, in particular.

\section{KEYWORDS}

Family. Children. Changes. Constitutional principles. Family power. 
O filho deve ter pelo pae respeito e veneração; porém, se a autoridade paterna se impõe pelo medo, póde afungentar a afeição, que é a base da sociedade parental entre paes e filhos. [...] A autoridade dos paes é um poder familiar, quer dizer, uma autoridade, que mantém os laços da família, e dentro do circulo das relações desta se circunscreve (BEVILÁQUA, 1979, p. 833 e 839).

\section{INTRODUÇÃO}

Além de fazerem parte da construção do nosso direito positivo, as primeiras luzes que acenaram mudanças nas atribuições dos direitos e deveres paternos iluminam, ainda hoje, a compreensão de todo o instituto.

Os cuidados para com os filhos, decorrentes do exercício do poder familiar e previstos em diversas normas, são atribuídos em primeiro lugar à família, independentemente de sua forma de constituição, sob a vigilância e a proteção da sociedade em geral e do Estado. Embora em nossa legislação haja previsão para a família e as entidades familiares estabelecidas pelo casamento, pela união estável e pela monoparentalidade, deve-se considerar que, conforme orienta o Professor Azevedo (2002, p. 321), os “parágrafos do aludido art. 226 não são taxativos, pois não é o Estado que determina como deva constituir-se a família, mas protege-a sob as variadas formas de constituição".

Atualmente a segurança garantida à família também encontra operabilidade na possibilidade, concedida ao julgador, de encontrar a melhor solução para os litígios considerando o caso concreto, algo que é facultado pelas legislações constitucional e infraconstitucional.

O presente estudo objetiva refletir sobre o exercício do poder familiar em relação à pessoa dos filhos, regulamentado pelo Código Civil de 2002, e sobre as alterações estabelecidas pela Lei $\mathrm{n}^{\circ}$ 13.058/2014, com ênfase nas relações familiares e nos princípios constitucionais.

O procedimento metodológico constitui-se de pesquisa bibliográfica e documental; a análise interpretativa fundar-se-á "na discussão teórica das normas ou categorias jurídicas abstratas” (SEVERINO, 1979, p. 60-62; ECO, 2010, p. 42; MARCHI, 2009, p. 66).

Para a investigação, far-se-ão algumas considerações no que diz respeito aos princípios constitucionais e às competências e concepções norteadoras do exercício dos direitos e deveres dos pais quanto à pessoa dos filhos previstos na legislação ordinária. Em seguida, buscar-se-á refletir acerca das alterações advindas com a Lei n. 13.058, de 22/12/2014, e, ao final, serão apresentados os resultados do presente estudo. 


\section{PRINCÍPIOS CONSTITUCIONAIS E SEU CARÁTER NORMATIVO: DIREITO PRIVADO}

A menção aos princípios constitucionais e a seu caráter normativo, a seguir, visa subsidiar a temática investigada e, por traduzir-se em árdua tarefa a ser enfrentada (mesmo para os renomados constitucionalistas), suas classificações e transformações no atual sistema jurídico serão sumariamente discutidas.

Também, para não se desviar do tema, as questões da constitucionalização do Direito Civil $^{1}$ e da interpretação e da hermenêutica constitucional ${ }^{2}$ serão inquiridas tão somente de maneira implícita, por estarem intimamente ligadas ao objeto de estudo.

A noção e a aplicação dos princípios modificaram-se. Tradicionalmente, ocorria a aplicação dos princípios gerais do direito nos termos previstos no art. $4^{\circ}$ da Lei de Introdução às Normas do Direito Brasileiro: “Quando a lei for omissa, o juiz decidirá o caso de acordo com a analogia, os costumes e os princípios gerais de direito”. Diniz (1999, p. 456 e 462) afirma que os princípios gerais do direito são como "normas de valor genérico que orientam a compreensão do sistema jurídico, em sua aplicação e integração, estejam ou não positivadas”.

Nesse sentido, Reale (1981, p. 300-301) ensina que eles “são enunciações normativas de valor genérico, que condicionam e orientam a compreensão do ordenamento jurídico, quer para a sua aplicação e integração, quer para a elaboração de novas normas” e são utilizados tanto no campo da pesquisa do Direito quanto no de sua aplicação prática. O ilustre mestre continua sua orientação no sentido de que aos princípios gerais, por possuírem função integradora bastante ampla, não cabe apenas a "tarefa de preencher ou suprir as lacunas da legislação”, e de que alguns deles "se revestem de tamanha importância que o legislador lhes confere força de lei, com a

\footnotetext{
1 Facchini Neto (2010, p. 56-57) leciona: "Em sentido mais moderno, pode-se encarar o fenômeno de constitucionalização do direito privado sob dois enfoques. No primeiro deles, trata-se da descrição do fato de que vários institutos que tipicamente eram tratados apenas nos códigos privados (família, propriedade etc.) passaram a ser disciplinados também nas constituições contemporâneas”. Num segundo aspecto, indicado com a expressão constitucionalização do direito civil, "mais amplo do que o primeiro, pois implica analisar as consequências, no âmbito do direito privado, de determinados princípios constitucionais, especialmente na área dos direitos fundamentais, individuais e sociais. Assim, o fenômeno pode ser compreendido sob determinada ótica hermenêutica, aquela da interpretação conforme a Constituição".

${ }^{2}$ Bastos (2014, p. 21 e 104), ao comentar sobre o objeto da interpretação constitucional e os princípios consagrados no texto constitucional, ensina: "O certo é que a interpretação tem sempre em vista um caso determinado. Já a Hermenêutica, como observado, tem por objeto os enunciados, aquelas fórmulas que serão utilizadas pelo intérprete. [...] os princípios consagrados constitucionalmente servem, a um só tempo, como objeto de interpretação constitucional e como diretriz para a atividade interpretativa”. Assim, "a interpretação é a atividade que procura imprimir uma vontade ao texto interpretado, de modo que este possa incidir no caso concreto", enquanto que a hermenêutica, "segundo Emilio Betti, é uma ciência do espírito que engloba o estudo da atividade humana de interpretar". Ladeado por renomados civilistas, Bittar (1990, p. 33) elucida: "a hermenêutica jurídica distinguir-se-ia como a teoria científica; a interpretação como a prática; e, a aplicação, como a modo técnico e aplicação”.
} 
estrutura de modelos jurídicos, inclusive no plano constitucional”, citando como exemplo "os princípios da isonomia (igualdade de todos perante a lei), de irretroatividade para a proteção dos direitos adquiridos etc.”. Verifica-se, outrossim, com fundamento nas lições de Reale (1981, p. 301), que nem todos os princípios “constam de textos legais” e nem todos têm “a mesma amplitude, pois há os que [se] aplicam neste ou naquele ramo do Direito”.

Ao comentar a modificação dos princípios gerais do direito e dos princípios constitucionais, Bonavides (2013, p. 284, 299-300) mostra que:

O ponto central da grande transformação por que passam os princípios reside, em rigor, no caráter e no lugar de sua normatividade, depois que esta, inconcussamente, proclamada e reconhecida pela doutrina mais moderna, salta dos Códigos, onde os princípios eram fonte de mero teor supletório, para as Constituições, onde em nossos dias se convertem em fundamento de toda ordem jurídica, na qualidade de princípios constitucionais.

Acerca dos princípios constitucionais, Bastos (1997, p. 154) leciona que são “aqueles valores albergados pelo Texto Maior a fim de dar sistematização ao documento constitucional, de servir como critério de interpretação e finalmente, o que é mais importante, espraiar os valores, pulverizá-los sobre todo o mundo jurídico”. Silva (1992, p. 85 e 87) mostra que os princípios previstos na Constituição Federal de 1988 "se traduzem em normas da Constituição ou que delas diretamente se inferem”; ou seja, são “ordenações que se irradiam e imantam os sistemas de normas”. Ainda, segundo o autor, os princípios se distinguem em constitucionais fundamentais e gerais do Direito Constitucional. Aqueles “integram o Direito Constitucional positivo” e traduzemse, entre outras, em normas fundamentais; os últimos "formam temas de uma teoria geral do Direito Constitucional” e envolvem “conceitos gerais, relações, objetos, que podem ter seu estudo destacado da dogmática jurídico-constitucional”.

Ainda, no que concerne aos princípios gerais, Silva (1992, p. 86) continua explicando que eles informam a ordem jurídica e decorrem "de certas normas constitucionais e, não raro, constituem desdobramentos (ou princípios derivados) dos fundamentais”. Isso ocorre, por exemplo, com o princípio individual, decorrente da declaração de direitos e da proteção à família.

É recorrente entre os constitucionalistas a afirmação de que com o advento da Constituição Federal de 1988 acirraram-se os debates em torno da valorização dos princípios e do desenvolvimento de algumas teorias que procuram explicar sua incidência no caso concreto (SOUZA NETO; SARMENTO, 2014, p. 379; SILVA, 2014, p. 30).

Silva (2014, p. 30) complementa ensinando que logo após a promulgação da atual Constituição as discussões davam-se em torno de sua classificação, distinção, etc., mas, no “desenrolar dos anos, algumas teorias desenvolvidas no exterior foram sendo assimiladas ao debate. 
A partir de um certo momento, passou a ser quase obrigatória a menção da contraposição entre regras e princípios, principalmente na versão desenvolvida por Robert Alexy”.

Igualmente, sobre os princípios, Souza Neto e Sarmento (2014, p. 379) comentam: sua valorização foi tanta que "hoje se reconhece, de forma praticamente incontroversa, o caráter plenamente normativo" dos mesmos e explicam que a "abertura dos princípios permite também que a Constituição se adapte mais facilmente às mudanças sociais, sem a necessidade de alterações formais tão frequentes no seu texto”, e garante segurança jurídica; logo, são fundamentais por inúmeras razões.

Referindo-se à contribuição do jurista alemão Robert Alexy, Canotilho (2007, p. 11591160) comenta que a “teoria da metodologia jurídica tradicional”, a qual distinguia normas e princípios, foi abandonada e substituída pela seguinte: “as regras e princípios são duas espécies de normas”.

Alexy (2014, p. 86) afirma serem normas as regras e os princípios, e que a distinção ocorre entre duas espécies de normas. Ainda, segundo o autor: “Ambos podem ser formulados por meio das expressões deônticas básicas do dever, da permissão e da proibição. Princípios são, tanto quanto as regras, razões para juízos concretos de dever-ser, ainda que de espécie muito diferente”.

Embora a aceitação da aplicação da teoria desenvolvida por Robert Alexy não seja unânime - e, segundo Silva (2014, p. 29), sua distinção entre regras e princípios “não é sempre compatível com as definições desses conceitos na doutrina brasileira” -, sua teoria é adotada por renomados autores nacionais e estrangeiros. Sarlet (2015, p. 83) informa: “adotamos a classificação das normas jurídicas (e constitucionais) em princípios e regras, seguindo, em linhas gerais, a já referida doutrina de Robert Alexy (por sua vez fortemente influenciado por Ronald Dworkin), amplamente difundida em nosso meio - notadamente por intermédio da obra de Gomes Canotilho”.

Nossa atual Constituição da República, como determinado em seu preâmbulo, sustenta-se nos princípios da soberania, da cidadania, da dignidade da pessoa humana, dos valores sociais do trabalho e da livre iniciativa e do pluralismo político. Além desses princípios informados pelo Estado democrático de direito existem outros na mesma Carta que subsidiam a aplicação e a interpretação dos direitos e garantias fundamentais, tais como os princípios da igualdade e da liberdade e outros que devem ser observados em litígios que envolvem questões em outras áreas do direito público e privado.

Quanto ao direito de família, Pereira (2005, p. 93) afirma: “toda e qualquer decisão deve, necessariamente, considerar os princípios” elencados na Carta Magna, porque sem “isto as decisões e concepções doutrinárias certamente se distanciarão do ideal de justiça ou ficarão contraditórias 
com um sistema jurídico que se pretende ético, no sentido universalizante em contraposição aos perigosos particularismos morais”.

Acerca dos princípios gerais, Madaleno (2015, p. 48) comenta que eles “integram a maioria dos sistemas jurídicos e no Brasil sua reafirmação tem sido constantemente observada diante da tendência de constitucionalização do Direito Civil e, notadamente, do Direito de Família”. Ainda, ladeado por alguns constitucionalistas, o autor explica que o princípio da dignidade da pessoa humana inserido no artigo $1^{\circ}$, III, da Carta Magna, atua, no âmbito constitucional, tanto como “princípio fundamental do Estado Democrático de Direito” quanto como princípio constitucional, situação em que "consagra os valores mais importantes da ordem jurídica, gozando de plena eficácia e efetividade, porque da alta hierarquia e fundamental prevalência, conciliando a segurança jurídica com a busca da justiça”.

No direito de família, vários princípios estão assentados no da dignidade da pessoa humana, e, segundo Madaleno (2015, p. 49), entre eles citam-se: o do melhor interesse da criança e do adolescente; a pluralidade de formas de família; a autonomia e menor intervenção estatal; a afetividade e a paternidade responsável.

Evidente que a menção a tais princípios é apenas exemplificativa, e que outros in casu - os quais tenham por finalidade proteger a criança e o adolescente, em particular, e a família, em geral devem, sempre que se fizerem necessários, ser utilizados.

\section{DO PÁTRIO PODER AO PODER FAMILIAR: DOS PODERES AOS DIREITOS}

A previsão do conjunto de direitos dos pais em relação à pessoa dos filhos decorrentes do exercício do pátrio poder é anterior à era da codificação. A menção, a seguir, ao rol de tais direitos - tanto pelas doutrinas que precederam o direito civil codificado, como pelo Código Civil brasileiro de 1916 - procura elencá-los, compreender sua gênese e a concepção do instituto adotada em cada época, subsidiando a discussão do tema.

A patria potestas, instituição exclusiva e reconhecida pelo Direito Romano, constituía-se pelos direitos atribuídos ao pater familias sobre a pessoa e os bens do filii familias. No início, tais direitos eram absolutos, mas a partir do século III d.C., devido ao prestígio exercido pelo cristianismo em relação às questões que dizem respeito ao direito de família e com as mudanças do ambiente social, das funções e da estrutura familiar e do parentesco, os direitos concedidos ao pater familias começaram a sofrer algumas restrições e se aproximaram “do conceito moderno de pátrio poder”. Tal instituição continuou sendo regulamentada durante todos os períodos que se sucederam 
ao Império Romano (ALVES, 2000b, p. 266; CORREIA; SCIASCIA, 1961, p. 120-121; GILISSEN, 2003, p. 611, 617-618). O Direito Romano na Alemanha, Espanha, França e em Portugal “aplicado à prática vigorou como direito comum até a codificação, em cada um deles, do direito privado, o que ocorreu, principalmente, no século XIX” (ALVES, 2000b, p. 59).

No Brasil, foi aplicada inicialmente a legislação portuguesa, reprodução do Direito Romano no estado em que o deixara o imperador Justiniano, com as modificações advindas com o tempo e os costumes (PEREIRA, 1918, p. 234). O Código Filipino (1603) vigeu no Brasil até a entrada em vigor do primeiro Código Civil brasileiro, em $1^{\circ}$ de janeiro de 1917 . Na Consolidação das Leis Civis, de Augusto Teixeira de Freitas (1858) (BEVILÁQUA, 1979, p. 14), encontram-se regulamentadas as atribuições do exercício do pátrio poder quanto à pessoa e aos bens do filho famílias (FREITAS, 2003, p. 167 e 191).

Na doutrina exposta por Lafayette Rodrigues Pereira (1918) observa-se que, na segunda metade do século XIX, também havia previsão expressa e regulamentada dos direitos decorrentes do pátrio poder sobre o "filho famílias”. Segundo o autor, juridicamente o pátrio poder é tudo que resulta do conjunto dos diversos direitos concedidos ao pai pela lei, e eles se dividiam em direitos que dizem respeito à pessoa e aos bens do “filho famílias” (PEREIRA, 1918, p. 234-236). Entre os primeiros competia aos pais:

1. Determinar o genero de educação que lhes convem dar, marcar o lugar em que devem recebe-la e escolher os mestres;

2. Te-los em sua companhia, sob sua guarda e sujeição;

3. Corrigi-los e castiga-los moderadamente em quanto forem menores;

4. Exigir que lhe prestem gratuitamente os serviços proprios de sua idade e condição;

5. Conceder ou negar-lhes consentimento para casamento;

6. Nomear-lhes tutor em testamento;

7. Fazer testamento por elles e nomear-lhes herdeiro para o caso de fallecerem em pupillar idade;

8. Representa-los nos actos da vida civil, quer judiciaes, quer extrajudiciaes;

9. Dar em nome delles queixas por crimes de que tenhão sido victimas;

10. Reclamar, por via de ação competente, que lhe sejão restituidos por quem injustamente os detenha sob seu poder (PEREIRA, 1918, p. 234-238, 241-244).

Acerca da concepção que subsidiava o instituto do pátrio poder, Pereira (1918, p. 234) mostra que nosso direito positivo, em vez de ter por fundamento a atribuição de direitos de educálo, de defendê-lo como pessoa e de zelar por seus bens, em razão da incapacidade do menor e da prevalência das antigas legislações, atribuem direitos aos pais, em relação aos seus filhos, que são inconciliáveis com a sua índole e razão de ser e os convertem, por uma singular inversão de seu fim, em pesado instrumento da prepotência, do orgulho e da cobiça dos pais. O autor anota que, graças ao progresso das luzes, algumas legislações modernas, entre elas os códigos civis francês, português e chileno, reconheceram a necessidade de separá-lo dos elementos estranhos, os quais o desvirtuam, 
para aproximá-lo do "typofilosofico" - denominação atribuída pelo autor -, cujo fundamento é a incapacidade do menor (PEREIRA, 1918, p. 234; RIVA, 2012, p. 70).

Na sequência, o Código Civil de 1916 elenca o conjunto de direitos e deveres atribuídos aos pais em razão do exercício do pátrio poder quanto à pessoa dos filhos:

Art. 384. Compete aos pais, quanto à pessoa dos filhos menores:

I. Dirigir-lhes a criação e educação;

II. Tê-los em sua companhia e guarda;

III. Conceder-lhes, ou negar-lhes consentimento para casarem;

IV. Nomear-lhes tutor, por testamento ou documento autêntico, se o outro dos pais lhe não sobreviver, ou o sobrevivo não puder exercitar o pátrio poder;

V. Representá-los, até os 16 anos, nos atos da vida civil, e assisti-los, após essa idade, nos atos em que forem partes, suprindo-lhes o consentimento.

VI. Reclamá-los de quem ilegalmente os detenha;

VII. Exigir que lhes prestem obediência, respeito e os serviços próprios de sua idade e condição.

O conceito de pátrio poder apresentado pela doutrina é praticamente unívoco e integra-se pelas atribuições por parte dos pais. Denomina-se pátrio poder o conjunto de direitos e deveres que a lei concede ao pai ou à mãe, sobre a pessoa e os bens do filho, até a maioridade ou emancipação. (BEVILÁQUA, 1933, p. 388; PONTES DE MIRANDA, 1983, p. 106).

Entre as diferenças em relação às legislações que o precederam, citam-se a transformação do instituto, que deixa de "ser um conjunto de direitos do pai sobre a pessoa dos filhos, amplos e ilimitados, para se tornar um complexo de deveres” (GOMES, 1995, p. 367), e a previsão contida no art. 379 do Código Beviláqua, a qual inclui não somente os filhos legítimos e legitimados, como no direito anterior, mas também os adotivos e legalmente reconhecidos.

A orientação anterior quanto à "razão de ser” da instituição do pátrio poder continua modificando-se. Pontes de Miranda (1983, p. 105-106 e 109) orienta, na época, que ela perde a “fereza romana, com que fôra transplantada para Portugal e depois para o Brasil”, e se constitui em um conjunto de direitos para que os pais possam melhor desempenhar a "sua missão de guardar, defender e educar os filhos, formando-os e robustecendo-os para a sociedade e a vida”. O Mestre conclui com a afirmação de que, a fim de atender "à concepção vigente do pátrio poder, pelo qual mais se protege do que se exercem poderes, o lugar para se tratar do pátrio poder”, sistematicamente, é no direito protetivo, ao lado da adoção, da tutela e da curatela e que a expressão poder não significa imposição e violência, mas sim a “exteriorização do querer” (PONTES DE MIRANDA, 1983, p. 106-107). Também Beviláqua (1979, p. 833) ensina que o “conjuncto de direitos é apenas tutelar, no sentido de que a sua organização visa mais o interesse do filho, que, por sua edade, necessita de um guia e protector”. 
A limitação do exercício do poder familiar, por meio da suspensão ou destituição do mesmo, também deveria dar-se "a bem dos interesses do filho e da propria sociedade" (BEVILÁQUA, 1933, p. 399), e até a década de 70 do século XX foi regulamentada, entre outros instrumentos legislativos, pelo Código Civil de 1916, art. 392 e seguintes; pelo Decreto n. 17.943A, de 12/10/1927 (Código Melo Matos), arts. 31 a 37; pela Lei n. 6.697, de 10/10/1979 (Código de Menores), arts. 21, 23 e 42, III, e pela Lei n. 6.515, de 26/12/1977, arts. $9^{\circ}$ e seguintes. Em todas essas legislações constata-se que, embora haja mudança na redação dos dispositivos legais, as práticas capazes de ensejar a suspensão e a destituição do poder familiar por parte dos pais guardam semelhanças quanto a vedarem qualquer forma de violência ou negligência e garantirem a inviolabilidade física e psicossocial dos filhos menores.

Percebe-se que a interpretação dos elementos constitutivos do pátrio poder pela doutrina seguindo os apelos de ilustres juristas como Clóvis Beviláqua (1933 e 1979), Pontes de Miranda (1983) e Orlando Gomes (1995) - deveria ser no sentido de proteger o filho. Nesse diapasão, Pereira (2000, p. 190) anota que, de conformidade com o movimento doutrinário, a partir do século XIX iniciou-se a defesa, em favor dos filhos ilegítimos, por um tratamento mais benéfico que “verberava os preconceitos e advogava a causa dos ilegítimos, condenados pelo pecado dos pais”. O autor informa que, assim como Beviláqua no Brasil, Laurent, no direito belga, e Cimbali, na Itália, “advogam para os filhos naturais tratamento humano”.

Não se pode deixar de anotar que os direitos e deveres atribuídos aos pais acompanham a trajetória da história da criança. A partir de fontes principalmente francesas, em seus estudos por meio da iconografia familiar, Philippe Ariès (1981, p. 10 e 156) mostra que o sentimento de infância era desconhecido na Idade Média. Após o século XVII, em razão de uma nova concepção de família, fundada sobre o respeito à dignidade da pessoa humana e presente nas fontes bíblicas ao lado do Estado, as relações entre os membros da família se transformaram, foi reconhecida a autoridade natural e divina do pai e da mãe e ocorreu uma mudança comportamental de densas obrigações morais e jurídicas (BADINTER, 1985, p. 31 e 43).

Todavia, na prática, a história também mostra que essa orientação ainda percorreu um longo e árduo caminho para que os filhos, enquanto crianças e adolescentes, fossem considerados sujeitos de direitos e detentores de proteção integral pela família, sociedade e Estado, o qual, desde a secularização do direito civil brasileiro, tem fiscalizado tal exercício (GOMES, 1995, p. 366).

A compreensão do pátrio poder, influenciada no âmbito interno por várias leis e, no âmbito externo, por diferentes instrumentos ditados pela Organização das Nações Unidas, dos quais o Brasil é signatário, foi se modificando durante quase todo o decorrer do século XX. 
No final da penúltima década do citado período, com a promulgação da Constituição Federal de 1988 e do Estatuto da Criança e do Adolescente de 1990, o pátrio poder consagra-se como "conjunto de direitos e deveres atribuídos aos pais, em relação à pessoa e aos bens dos filhos não emancipados, tendo em vista a proteção destes” (AZEVEDO, 2013, p. 277-278).

Em seguida, diante de uma "nova família”, que se firma "fundamentalmente como grupo de afetividade e companheirismo" (VILLELA, 1979, p. 412) e se estrutura "nas relações de autenticidade, afeto, amor, diálogo e igualdade” (LEITE, 1991, p. 367), o Código Civil de 2002 substituiu a expressão “pátrio poder” por “poder familiar”, mas manteve a redação do art. 348, do Código precedente.

\subsection{A PROMOÇÃO DOS DIREITOS E DEVERES E AS NOVAS IDEIAS: ARTIGO 1.634, CÓDIGO CIVIL DE 2002}

A denominação “poder familiar”, no art. 1.630 e seguintes do Código Civil brasileiro de 2002, ainda não é, segundo parte da doutrina nacional e estrangeira, a mais adequada, porque remete ao sentido de "poder".

Embora essa expressão seja adotada por grande parte das legislações modernas, Azpiri (2005, p. 469) anota há mais de uma década, na Argentina, que a expressão utilizada, patria potesta, não reflete o atual sentido da instituição, pois tende a enfatizar que se trata de beneficiar os filhos, quando também deveria mostrar os deveres e as responsabilidades dos pais exercidos para lograr a proteção e a formação integral dos filhos. Bossert e Zannoni (2001, p. 556) sustentam que, embora a lei enuncie concretamente os direitos e deveres quanto ao exercício da patria potesta, entranham-se a eles, entre outros, a autoridade dos pais.

Na Itália, apesar de a legislação adotar a expressão “Della potestà dei genitori” (art. 315 e seguintes do Código Civil italiano), Bianca (2005, p. 329) conceitua, na doutrina, a potestà dei genitori, no sentido de autoridade que o ordenamento atribui aos pais no interesse exclusivo do filho menor, cujas atribuições dizem respeito aos aspectos pessoais, como cuidados e educação, e patrimoniais, como sua representação diante dos interesses econômicos. Apreende-se ainda, dos estudos do autor, que essa autoridade denota responsabilidade e não contrasta com a ideia de família nem com o princípio da igualdade recíproca, porque os poderes são conferidos aos pais em razão da incapacidade do filho e têm por finalidade, entre outros, sua proteção integral, a formação de sua personalidade e a promoção de sua autonomia (BIANCA, 2005, p. 329).

Na França, o art. 371-1 do Código Civil adota a expressão “autoridade parental”, a qual se constitui pelo conjunto de direitos e deveres cuja finalidade é o interesse dos filhos, para protegê-los 
em sua segurança, saúde e moralidade, para garantir a sua educação e permitir seu desenvolvimento e o respeito à sua pessoa. Ainda, os pais devem tomar, de comum acordo, as decisões que os afetam, de acordo com sua idade e grau de maturidade e, na doutrina, Maluarie (1994, p. 428) explica que a palavra autoridade, ao contrário da patria potestas (puissancepaternelle), traduz a evolução da lei e denota, entre outros, proteção, respeito, responsabilidade dos pais para com seus filhos menores. Explica ainda que, com a perda da autoridade, toda a família é afetada.

No Brasil, Gomes (1985, p. 368) explica, acompanhado por outros civilistas que comentam o Código Civil atual, que, apesar da concepção moderna, a qual vê no pátrio poder [hoje poder familiar] "mais um conjunto de deveres do que de prerrogativas, a relação paterno-filial conserva a natureza de uma relação de autoridade”. Isso porque há, entre eles, um vínculo de subordinação; assim, os genitores têm poder de mando, e a prole, o dever de obediência. Não obstante a isso, esse “poder hierárquico” deve ter "exercício no interesse do filho, não sendo ilimitado na sua extensão nem no seu uso".

Tendo em vista a importância, para melhor compreensão da expressão “autoridade”, do conceito etimológico, verifica-se que, derivado do latim auctoritas, aplica-se na terminologia jurídica, entre outros, como “o direito que se assegura a outrem para praticar determinados atos relativos a pessoas” (SILVA, 1982, p. 253). Por seu turno, “autoridade parental” pode ser entendida como o direito assegurado aos parentes - in casu, aos pais - para praticar determinados atos relativos aos filhos.

Lôbo (2009, p. 271) comenta que a denominação “autoridade parental” é mais adequada do que “poder”, porque esta última evoca “uma espécie de poder físico sobre a pessoa do outro”. Nesse sentido, Fachin (2003, p. 243) orienta que a "autoridade parental revela um conjunto de circunstâncias que vão informar as características do exercício desses direitos e a assunção de correspectivos deveres. Não se trata de 'poder', nem propriamente de 'função'. Não há relação de subordinação”.

A denominação “autoridade parental” também é reconhecida por Leite (2003, p. 213), para quem ela "recobre um conjunto de deveres cuja simplicidade do dispositivo legal não permite avaliar a complexidade e a responsabilidade”. O mestre ensina, ainda, que em decorrência dessa autoridade os genitores, além de deterem os deveres de sustento, guarda e educação dos filhos (art. 1.566 do Código Civil de 2002), também devem protegê-los “em todas as suas necessidades, de ordem material ou espiritual, velando pelo seu pleno desenvolvimento na segurança, saúde e moralidade”, e também quanto à administração legal de seus bens e ao gozo dos mesmos (LEITE, 2003, p. 245). 
Em seu memorável estudo acerca da "Desbiologização da Paternidade”, Villela (1979, p. 401) leciona que o conceito de paternidade "poderia ter-se formado" em uma "linha de acomodação, que, partindo do fato biológico, então incontrolável, chegava aos rudimentares predicamentos sociais, jurídicos e religiosos, que lhe garantiam um lugar ao sol no incipiente thesaurus da cultura"; dessa forma, embora a paternidade tenha em sua origem uma "base biológica”, ela "não é um fato da natureza, mas um fato cultural”.

Ressalta-se que a autoridade dos pais em relação aos filhos também é reconhecida fora da seara jurídica. Parseval (1986, p. 236) verificou, nos resultados de sua pesquisa, cujos sujeitos eram homens e segundo uma perspectiva etnológica e psicanalítica, que o pai, biológico ou não, exerce inúmeras funções, entre as quais estão as sociais e as educativas, e representa, ao lado da mãe, o papel de detentor de autoridade.

De acordo com as determinações trazidas pela Constituição Federal de 1988 e pelo Estatuto da Criança e do Adolescente de 1990, no Código Civil vigente o poder familiar consagrase como um "munus que deve ser exercido, fundamentalmente, no interesse do filho” (AZEVEDO, 2013, p. 285). Monteiro e Silva (2010, p. 497) acrescentam que, além dos filhos, o poder familiar deve ser exercido no interesse da família, com a aplicação do princípio da paternidade responsável, o qual está ínsito no art. 226, § 7º da Constituição Federal de 1988.

Lôbo (2009, p. 271) aponta, no tocante ao munus público, que de sua constituição são ressaltados os deveres, e Fachin (2003, p. 246) destaca que seu "significado transcende o interesse pessoal, e o exercício da autoridade parental não consiste necessariamente no atendimento do interesse privado".

Para indicar a faculdade de agir dos pais, alguns autores comentam que não se deve utilizar a expressão “obrigação”, mas sim “deveres”, a qual é adequada para as relações familiares e não para as patrimoniais (AZPIRI, 2005, p. 470; BOSSERT; ZANNONI, 2001, p. 555) ou de direito real (GOMES, 1985, p. 368).

O art. 1.634 do Código Civil, antes da alteração apresentada pela Lei n. 13.058/2014, trazia a seguinte redação:

Art. 1.634. Compete aos pais, quanto à pessoa dos filhos menores:

I - dirigir-lhes a criação e educação;

II - tê-los em sua companhia e guarda;

III - conceder-lhes ou negar-lhes consentimento para casarem;

IV - nomear-lhes tutor por testamento ou documento autêntico, se o outro dos pais não lhe sobreviver, ou o sobrevivo não puder exercer o poder familiar;

V - representá-los, até aos dezesseis anos, nos atos da vida civil, e assisti-los, após essa idade, nos atos em que forem partes, suprindo-lhes o consentimento;

VI - reclamá-los de quem ilegalmente os detenha; 
VII - exigir que lhes prestem obediência, respeito e os serviços próprios de sua idade e condição.

As competências elencadas nos sete incisos acima compreendem respectivamente, em linhas gerais e de forma não exaustiva, os seguintes direitos-deveres: cuidado material, moral e educacional (inciso I); de ter os filhos em sua companhia e guarda "para poder fiscalizar sua atuação" (inciso II); de conceder ou negar o consentimento para casarem e, nos termos da lei, nomear-lhes tutor (incisos III e IV); de representá-los e assisti-los (inciso V), de não "confiar seu filho a outrem sabendo que corre risco moral e material” (àquele que tem a guarda), e, por isso, pode reclamá-los de quem ilegalmente os detenha (inciso VI) e "a aplicação de corretivos moderados, pois, se os castigos forem imoderados, tal fato caracteriza maus tratos, com perda do poder familiar (art. 1.638, inciso I, do Código Civil)” (AZEVEDO, 2013, p. 280-281 e 285).

Acerca do conjunto dos direitos e dos deveres acima, Madaleno (2015, p. 720) comenta que ele "interage no propósito de atribuir aos pais uma função de bem desempenharem no exercício do seu poder familiar” e que os pais devem valer-se "da sintonia de seus deveres e dos seus direitos como pais, na tarefa de bem administrarem a pessoa e os bens dos seus filhos, com vistas a alcançarem a integral e estável formação de seus filhos”.

Nosso ordenamento jurídico, além de reafirmar tais direitos e deveres em outras leis ordinárias e especiais, também prevê a reciprocidade de vários direitos entre pais e filhos; por isso, se os pais, em razão da idade avançada, carência ou enfermidade, necessitarem de cuidados, os filhos serão os devedores (CF/1988, art. 229 e 230; Lei n. 10.741/2003, art. $3^{\circ}$ e 11).

Além disso, o ilustre professor das Arcadas explica: como o poder familiar constitui um munus a ser exercido no interesse dos filhos, "o Estado o controla, estatuindo na lei os casos em que o titular deve ser privado do seu exercício, temporária ou definitivamente” (AZEVEDO, 2013, p. 280-281 e 285). Tais situações estão fundamentadas nos arts. 1.637 e 1.638 do Código Civil de 2002.

Como visto, os casos de suspensão ou destituição do poder familiar guardam semelhanças com os previstos nas legislações anteriores e ocorrem, entre outras, em situações de negligência, de abusos e de maus exemplos que comprometam a saúde, a segurança e a moralidade do filho. Além disso, anota-se que, nesses casos, há clara ligação entre essas práticas e a falta de cumprimento dos deveres paternos perante a família (ELIAS, 2008, p. 19). 


\subsection{O PODER FAMILIAR QUANTO À PESSOA DOS FILHOS: LEI N. 13.058/2014}

No tocante aos atributos do poder familiar em relação à pessoa dos filhos, os dados levantados, apesar de corresponderem à ponta de um iceberg, são capazes de mostrar que as determinações do art. 1.634 do Código Civil de 2002, embora bastante discutidas, denotam pouca divergência doutrinária e jurisprudencial.

Sobre a compreensão dos atributos (art. 1.634, Código Civil de 2002) percebe-se que, se por um lado, não há controvérsias, por outro, várias são as circunstâncias que ensejam sua aplicação, e sobre essas não há consenso algum. O julgador deve ater-se sempre, então, ao que melhor preservar a dignidade e atender aos interesses dos filhos in casu, enquanto crianças e adolescentes.

Apesar disso, foi sancionada a Lei $\mathrm{n}^{\circ}$ 13.058/2014, para alterar, entre outros, o art. 1.634 da Lei n ${ }^{0}$ 10.406/2002, e estabelecer o significado da expressão “guarda compartilhada”. Segundo a Lei, o citado artigo do Código Civil/2002 passa a ter a seguinte redação:

\footnotetext{
Art. 1.634. Compete a ambos os pais, qualquer que seja a sua situação conjugal, o pleno exercício do poder familiar, que consiste em, quanto aos filhos:

I - dirigir-lhes a criação e a educação;

II - exercer a guarda unilateral ou compartilhada nos termos do art. 1.584;

III - conceder-lhes ou negar-lhes consentimento para casarem;

IV - conceder-lhes ou negar-lhes consentimento para viajarem ao exterior;

$\mathrm{V}$ - conceder-lhes ou negar-lhes consentimento para mudarem sua residência permanente para outro Município;

VI - nomear-lhes tutor por testamento ou documento autêntico, se o outro dos pais não lhe sobreviver, ou o sobrevivo não puder exercer o poder familiar;

VII - representá-los judicial e extrajudicialmente até os 16 (dezesseis) anos, nos atos da vida civil, e assisti-los, após essa idade, nos atos em que forem partes, suprindo-lhes o consentimento;

VIII - reclamá-los de quem ilegalmente os detenha;

IX - exigir que lhes prestem obediência, respeito e os serviços próprios de sua idade e condição.
}

A princípio registra-se, nos termos da redação dada ao citado artigo, que o destaque “qualquer que seja a sua situação conjugal” mostra-se indevido, pois há muito tempo o pleno exercício do poder familiar não guarda relação alguma com a situação conjugal dos pais; aliás, o termo "conjugal” deve ser interpretado de forma genérica. Na sequência, nota-se que a extensão anunciada dos atributos do exercício do poder familiar quanto à pessoa dos filhos é apenas de denominação, já que, ou estavam determinados em leis anteriores e foram mantidos ou estão previstos em outras leis vigentes; ou, ainda, são decorrência da guarda compartilhada já regulamentada desde a edição da Lei n. 11.698, de 2008.

Entre os incisos acrescidos estão os de números IV, V e VII. Quanto ao primeiro deles "IV - conceder-lhes ou negar-lhes consentimento para viajarem ao exterior" -, apreende-se que a 
determinação já está prevista na legislação especial (Estatuto da Criança e do Adolescente de 1990, art. 84).

Mesmo diante de ruptura da sociedade conjugal ou da união estável, ou nos casos de monoparentalidade, e seja qual for a espécie de guarda, a faculdade concedida aos pais, bem como seus deveres - inclusive, a fim de autorizar os filhos a viajarem ao exterior -, são os mesmos; aliás, o não exercício dessa prerrogativa conduz inevitavelmente ao descumprimento dos deveres paternos.

Quanto ao inciso seguinte - "V - conceder-lhes ou negar-lhes consentimento para mudarem sua residência permanente para outro Município”, anota-se que: 1) no caso da guarda não compartilhada, o não detentor da guarda tem assegurado o direito de visitas e todos os demais direitos decorrentes do poder familiar, tais como o de criar, cuidar e educar, e que 2) no caso da guarda compartilhada, essa previsão já consta no art. 1.583, § $3^{\circ}$ do Código Civil de 2002, com a nova redação da Lei n. 13.058/2014. Isso porque, se o objetivo da citada lei é o de compartilhar os cuidados com a prole, e se ela não veda a possibilidade de os filhos morarem em outra cidade, torna-se evidente caber aos pais o dever de consentir ou não com a mudança de residência da prole, tanto para outra cidade como para outro estado ou país, e, em caso de discordância, cabe ao juiz decidir acerca dos motivos (art. 1.631, parágrafo único, Código Civil de 2002). Acresce-se a isso, nos termos da lei em comento: “a cidade considerada base de moradia dos filhos será aquela que melhor atender aos interesses dos filhos".

No entanto, é oportuno destacar o legado por Simão (2015, p. 1), ao comentar tal determinação prevista no então Projeto de Lei 117/2013: “este dispositivo é absolutamente nefasto ao menor e ao adolescente. Preconiza ele a dupla residência do menor em contrariedade às determinações de todos os especialistas da área e da psicanálise”.

O último inciso adicionado, ao qual foi acrescida a representação extrajudicial, tem a seguinte redação: "VII - representá-los judicial e extrajudicialmente até os 16 (dezesseis) anos, nos atos da vida civil, e assisti-los, após essa idade, nos atos em que forem partes, suprindo-lhes o consentimento". Importa observar: 1) tal previsão constava na doutrina exposta por Lafayette Rodrigues Pereira (1918, p. 234), ao orientar que cabia aos pais representar seus filhos nos atos judiciais e extrajudiciais; 2) há responsabilidade dos pais por atos dos filhos e cabe à lei regulamentar a representação judicial, porque a extrajudicial está implícita e decorre dos vários atributos do poder familiar, como é o caso dos incisos I e II do art. 1.634 do Código Civil de 2002.

No caso da guarda, Cahali (2006. p. 145-146) mostra que seu conceito foi se abrandando no tempo, sendo ela um dos atributos do poder familiar, "mas não se exaure nele nem com ele se 
confunde; em condições tais, a guarda pode existir sem o pátrio poder, como, reciprocamente, este pode ser exercido sem a guarda”. Além disso, como orienta Grisard Filho (2013, p. 50), a guarda também é uma função decorrente do “dever constitucional de assistência aos filhos menores” e nela está implícito o dever de assegurar todos os meios para o exercício da cidadania; 3) para não alongar a discussão, cabe apresentar as explicações do professor das Arcadas, Álvaro Villaça Azevedo (2012, p. 18), segundo o qual a pessoa incapaz deve "ser representada, por seus pais tutores ou curadores, conforme o caso", e atuar "sempre por intermédio de seus representantes".

Nesse sentido, verifica-se que tanto a incapacidade absoluta como a relativa são supridas por alguém que agirá em seu nome, ou seja, pela representação do filho, desde a concepção até os 16 anos, e pela assistência, após essa idade e até os 18 anos, nos atos em que for parte. Também, de acordo com a lei, como quando há colisão de interesses entre pais e filhos, existe a possibilidade de nomeação de curador especial para o filho (art. 1.692, CC) ou, em outras situações, de tutor (arts. 1.729 e $1.731, \mathrm{CC})$.

Anota-se que, na prática, a citada “representação extrajudicial” sempre existiu sem nenhum problema apregoado e, juridicamente, se fosse necessária, tal medida estava implícita e explicitamente assegurada antes da entrada em vigor da Lei de 2014. Assim, a extensão das demais prerrogativas, atributos ou competências, além de nada inovar também não agrega em termos do que se concebe ao poder familiar e in casu, a exemplo do que ocorre com a mesma Lei no tocante à guarda compartilhada, como manifesta Simão (2015, p. 1): “A lei não é, por si, a solução do problema, como parecem preconizar os defensores do PL 117/2003 [atual Lei n. 13.058/2014]”.

Assim, a redação do art. 1.634, trazida pela Lei $n^{0}$ 13.058/2014, além de não inovar, ainda se mostra frágil para sugerir mudanças, pois abrange quase todos os direitos-deveres anteriormente previstos, e não indica nenhuma alteração capaz de ampliar a proteção da criança ou do adolescente quanto à interpretação de uma nova concepção a ser adotada.

Essas ponderações encontram ressonância também nas “diretrizes básicas seguidas pela comissão revisora do Código Civil de 2002”. A redação anterior do art. 1.634 é a mesma do Código Civil de 1916 e não deve ter sido em vão que citada comissão buscou preservar o "Código Civil anterior sempre que fosse possível, pela excelência técnica do seu texto e diante da existência de um posicionamento doutrinário e jurisprudencial já consubstanciado sobre temas nele constantes” (TARTUCE, 2012, p. 74).

Atualmente, os atributos decorrentes do exercício do poder familiar elencados no art. 1.634 do Código Civil de 2002 devem ser lidos sob a perspectiva da proteção integral da criança e do 
adolescente, e interpretados, segundo Delgado (2014, p. 4), de acordo com os valores vigentes na sociedade.

\section{CONCLUSÃO}

Os dados mostram que o instituto investigado desafiou o tempo; com raízes no Direito Romano e sendo aplicado nos períodos subsequentes a este Direito, o poder familiar está previsto em quase todos os sistemas jurídicos modernos e é considerado um dos mais importantes do Direito Privado. Ao se comparar os dados, verificou-se ainda que, apesar de em sua "razão de ser" o instituto ter sofrido mudanças, vários direitos entre pais e filhos foram mantidos pelas sucessivas legislações, com as devidas alterações decorrentes, entre outras, das mudanças do ambiente social, das funções e da estrutura familiar e do parentesco.

Constatou-se que, para se chegar ao reconhecimento da condição do filho como a concebemos hoje, foi preciso transpor uma longa e árdua trajetória, que se inicia com os fundamentos cristãos, passa pela consideração de sua incapacidade - apesar das intercessões de iluminados juristas, os quais ressaltavam a finalidade protetiva do instituto -, percorre um caminho que desvaloriza sua condição em favor da vontade dos pais para, finalmente, rumar em direção a uma nova codificação que consagra a eles um conjunto de direitos capaz de assegurar-lhes, “com absoluta prioridade, a efetivação dos direitos referentes à vida, à saúde, à alimentação, à educação, ao esporte, ao lazer, à profissionalização, à cultura, à dignidade, ao respeito, à liberdade e à convivência familiar e comunitária”, além de colocá-los a salvo de "qualquer forma de negligência, discriminação, exploração, violência, crueldade e opressão, punido na forma da lei qualquer atentado, por ação ou omissão, aos seus direitos fundamentais” (arts. $4^{\circ}$ e $5^{\circ}$ da Lei n. 8.069/1990).

Nota-se que o instituto também é abrilhantado pela reciprocidade de direitos e deveres entre pais e filhos, já que todos os cuidados para com estes devem se reverter em favor daqueles quando na velhice ou enfermidade necessitarem, conforme previsto tanto pela Constituição Federal de 1988 como pela legislação ordinária e especial. Essa orientação mantém estrita relação com a solidariedade social (art. 3º I, da CF/1988) e, nas relações privadas, está presente na solidariedade familiar.

Da análise do material coligado infere-se que a atual concepção do poder familiar sofre influências de diversos fatores sociais e culturais e deve ser interpretada segundo os valores presentes na sociedade, os quais têm como primeira finalidade as proteções física, mental, moral, espiritual e social e a defesa dos interesses dos filhos e da família. Anota-se que a interpretação e a 
execução desse novo entendimento também são permitidas a partir da leitura do atual Código Civil, tanto em razão de suas cláusulas gerais como pela possibilidade de haver interação entre as normas jurídicas.

Os dados indicaram que no Brasil, a exemplo do ocorrido em outros países, as mudanças na letra da lei, no que concerne aos direitos e deveres paternos estabelecidos no art. 1.634 do Código Civil de 2002, não foram tão significativas quanto a concepção das atribuições que circundam o instituto do poder familiar.

Ao investigar os princípios constitucionais e o caráter normativo dos mesmos, tinha-se como objetivo subsidiar a compreensão do tema - o que ocorreu, pois após o levantamento e a análise dos dados foi possível: refletir acerca da possibilidade do diálogo entre o direito de família (em geral, e seu instituto do poder familiar, em particular) e os princípios constitucionais; assinalar que naquele ramo do direito, como ocorre com o do direito constitucional, a solução dos litígios nem sempre está adstrita à letra da lei; indagar sobre a incidência de alguns princípios constitucionais nas relações entre particulares.

Portanto, para a segurança dos filhos, crianças e adolescentes, a criação de novas normas nem sempre se mostra como condição sine qua non, já que é majoritariamente aceito pela doutrina e pela jurisprudência pátrias que, em caso de litígio, o julgador pode optar sempre pela solução que assegure melhores efeitos na prática, e essa possibilidade existe por meio da aplicação dos princípios constitucionais, cuja interpretação, na órbita privada, segundo as lições do mestre Carlos Alberto Bittar (1990, p. 22), “deve perfazer-se não pela letra do texto, mas pelo espírito da Carta”, ou seja, “à luz das diretrizes expostas” na Constituição de 1988.

No tocante à Lei n. 13.058, de 2014, os dados sugerem que, nos termos da redação do citado art. 1.634, a extensão das competências dos pais em relação aos filhos é apenas de denominação, já que, ou estavam previstas em leis anteriores e foram reintegradas no atual ordenamento jurídico, ou constam em outras leis vigentes, ou foram decorrência da guarda compartilhada já regulamentada mesmo antes da lei em comento.

Além disso, o levantamento aponta que, ao não inovar e não contribuir para uma nova concepção do poder familiar, a citada Lei de 2014, a exemplo de outras leis ordinárias que alteram leis ordinárias, pode se mostrar desnecessária, por tutelar objeto já juridicamente regulamentado.

Observa-se na legislação e nas doutrinas nacional e estrangeira que, embora existam denominações diferentes para designar as atribuições decorrentes do exercício do poder familiar, todas têm em comum os cuidados no plano pessoal e patrimonial dos filhos, para sua proteção e formação integral, e que a denominação “autoridade parental”, utilizada pelas modernas legislações 
e por alguns doutrinadores, associa-se aos deveres, tais como os de alimentar, proteger, cuidar, educar, apoiar; à noção de responsabilidade dos pais - responsabilidade que é necessária para a segurança do filho e da família; ao direito assegurado aos pais para praticarem determinados atos relativos aos filhos; à função dos pais como detentores de autoridade.

Ao mesmo tempo, de acordo com as atuais concepções jurídicas do instituto, foi possível inferir que, para os pais desempenharem suas funções, um dos caminhos possíveis deve passar pela valorização de sua autoridade pela família. Deve passar, ainda, pelos deveres, tanto dos pais de exercerem a autoridade no interesse do filho, como do filho em respeitar seus pais.

Certamente, a valorização da autoridade dos pais deve seguir as lições de iluminados juristas que sempre estiveram adiante de seu tempo, como as trazidas na epígrafe: fundar-se na “afeição, que é a base da sociedade parental”, e ter por escopo manter “os laços da família”.

\section{REFERÊNCIAS}

ALEXY, Robert. Teoria dos direitos fundamentais. Tradução de Virgílio Afonso da Silva. 2. ed. São Paulo: Malheiros, 2014.

ALVES, José Carlos Moreira. Direito romano. 13. ed. rev. Rio de Janeiro: Forense, 2000a. v. I.

. Direito romano. 6. ed. rev. e acrescentada. Rio de Janeiro: Forense, 2000b. v. II.

ARIÈS, Philippe. História social da criança e da família. Tradução de Dora Flaksman. 2. ed. Rio de Janeiro: LTC, 1981.

AZEVEDO, Álvaro Villaça. Direito de família. São Paulo: Atlas, 2013.

. Estatuto da família de fato: de acordo com o novo Código Civil, Lei n. 10.406, de 10-012002. 2. ed. São Paulo: Atlas, 2002.

. Teoria geral do direito civil. São Paulo: Atlas, 2012.AZPIRI, O. Jorge. Derecho de familia. Buenos Aires: Hammurabi, 2005.

BADINTER, Elisabeth. Um amor conquistado: o mito do amor materno. Tradução de Waltensir Dutra. 10. impr. Rio de Janeiro: Nova Fronteira, 1985.

BASTOS, Celso Ribeiro. Curso de direito constitucional. 18. ed. ampl. e atual. São Paulo: Saraiva, 1997.

2014.

. Hermenêutica e interpretação constitucional. 4. ed. rev. e atual. São Paulo: Malheiros,

BEVILÁQUA, Clóvis. Código Civil dos Estados Unidos do Brasil. 4. tir. Edição histórica. Rio de Janeiro: Editora Rio, 1979. 
Direito da familia. 5. ed. Rio de Janeiro: Freitas Bastos, 1933.BIANCA, C. Massimo. Diritto civile: la famiglia - le successioni. 4. ed. Milano: Dott. A. Giuffrè, 2005. v. II.

BITTAR, Carlos Alberto. O direito civil na Constituição de 1988. São Paulo: Editora Revista dos Tribunais, 1990.

BONAVIDES, Paulo. Curso de direito constitucional. 28. ed. atual. São Paulo: Malheiros, 2013.

BOSSERT, Gustavo A.; ZANNONI, Eduardo A. Manual de derecho de familia. 5. ed. Buenos Aires: Astrea, 2001.

CAHALI, Yussef Said. In: CURY, Munir (Coord.). Estatuto da criança e do adolescente comentado: comentários jurídicos e sociais. 8. ed. São Paulo: Malheiros, 2006.

CANOTILHO, J. J. Gomes. Direito constitucional e teoria da constituição. 7. ed. Coimbra, Portugal: Edições Almedina, 2007.

CORREIA, Alexandre; SCIASCIA, Gaetano. Manual de direito romano. 4. ed. rev. e aum. São Paulo: Saraiva, 1961. v. I.

DELGADO, Mário Luiz. Violência patrimonial contra a mulher. 02/09/2014. Disponível em: <http://ibdfam.org.br/artigos/971/Viol\%C3\%AAncia+patrimonial+contra+a+mulher+>. Acesso em: 7 out. 2014.

DINIZ, Maria Helena. Compêndio de introdução à ciência do direito. 11. ed. atual. São Paulo: Saraiva, 1999.

ECO, Umberto. Como se faz uma tese. Tradução de Gilson Cesar Cardoso de Souza. 23. ed. São Paulo: Perspectiva, 2010.

ELIAS, João Roberto. Comentários ao Estatuto da Criança e do Adolescente: lei n. 8.069, de 13 de julho de 1990. 3 ed. São Paulo: Saraiva, 2008.

FACCHINI NETO, Eugênio. Reflexões histórico-evolutivas sobre a constitucionalização do direito privado. In: SARLET, Ingo Wolfgang (Org.). Constituição, direitos fundamentais e direito privado. 3. ed. rev. e ampl. Porto Alegre: Livraria do Advogado, 2010.

FACHIN, Luiz Edson. Direito de família: elementos críticos à luz do novo código civil brasileiro. 2 ed. Rio de Janeiro: Renovar, 2003.

FRANÇA. Code Civil. 109 édition. Paris: Dalloz, 2010.

FREITAS, Augusto Teixeira de. Consolidação das leis civis. Ed. fac-sim. Brasília: Senado Federal, 2003. v. I.GILISSEN, John. Introdução histórica ao direito. Tradução de A. M. Hespanha e L. M. Macaísta Malheiros. 4. ed. Lisboa: Fundação Calouste Gulbenkian, 2003.

GOMES, Orlando. Direito de família. 8. ed. Rio de Janeiro: Forense, 1995.

ITÁLIA. Codice Civile e Leggi Complementari. Milano: Editore Ulrico Hoepli, 2011. 
LEITE, Eduardo de Oliveira. Famílias monoparentais: a situação jurídica de pais e mães solteiros, de pais e mães separados e dos filhos na ruptura da sociedade conjugal. 2. ed. rev., atual. e ampl. São Paulo: Editora Revista dos Tribunais, 2003.

. Tratado de direito de família: origem e evolução do casamento. Curitiba: Juruá, 1991.LÔBO, Paulo. Direito civil: famílias. 2 ed. São Paulo: Saraiva, 2009.

MADALENO, Rolf. Curso de direito de família. 6. ed. rev., atual e ampl. Rio de Janeiro: Forense, 2015.

MALAURIE, Philippe. Cours de droit civil: la famille. 4. ed. Paris: Éditions Cujas, 1994. t. III.

MARCHI, Eduardo C. Silveira. Guia de metodologia jurídica. 2. ed. São Paulo: Saraiva, 2009. MONTEIRO, Washington de Barros; SILVA, Regina Beatriz Tavares da. Curso de direito civil: direito de família. 40. ed. São Paulo: Saraiva, 2010. v. 2.

PARSEVAL, Geneviève Delaisi de. A parte do pai. Tradução de Theresa Cristina Stummer. Porto Alegre: L\&PM, 1986.

PEREIRA, Lafayette Rodrigues. Direitos de família. Anotações e adaptações ao Código Civil, por José Bonifácio de Andrada e Silva. Rio de Janeiro: Virgilio Maia \& Comp., 1918.

PEREIRA, Rodrigo da Cunha. Princípios fundamentais: norteadores para o direito de família. Belo Horizonte: Del Rey, 2005. PONTES DE MIRANDA, Francisco Cavalcanti. Tratado de direito privado. 4. ed. São Paulo: RT, 1983. t. IX.

REALE, Miguel. Lições preliminares de direito. 9. ed. rev. São Paulo: Saraiva, 1981.

RIVA, Léia Comar. União estável sob a perspectiva do parentesco por afinidade. 2012. $251 \mathrm{f}$. Tese (Doutorado em Direito) - Faculdade de Direito da Universidade de São Paulo, São Paulo, 2012.

SARLET, Ingo Wolfgang. Dignidade (da pessoa) humana e direitos fundamentais na Constituição Federal de 1988. 10. ed. rev., atual. e ampl. Porto Alegre: Livraria do Advogado Editor, 2015.

SEVERINO, Antônio Joaquim. Metodologia do trabalho científico. 4. ed. rev. São Paulo: Cortez \& Moraes Ltda, 1979.

SILVA, José Afonso da. Curso de direito constitucional positivo. 8. ed. rev. e ampl. São Paulo: Malheiros, 1992.

SILVA, Virgílio Afonso da. A constitucionalização do direito: os direitos fundamentais nas relações entre particulares. 1. ed., 4. tir. São Paulo: Malheiros, 1992.

SIMÃO, José Fernando. Guarda compartilhada obrigatória. Mito ou realidade? 24/04/2015. Disponível em: <http://www.professorsimao.com.br/artigos/artigo.aspx?id=312>. Acesso em: 19 maio 2015.

SOUZA NETO, Cláudio Pereira; SARMENTO, Daniel. Direito constitucional: teoria, história e métodos de trabalho. 2. ed. Belo Horizonte: Fórum, 2014. 
TARTUCE, Flávio. Direito civil: lei de introdução e parte geral. 8. ed. rev. e atual. São Paulo: Método, 2012. v. 1.

VILLELA, João Baptista. A desbiologização da paternidade. Revista da Faculdade de Direito da Universidade Federal de Minas Gerais. Belo Horizonte: ano XXVII, n. 21, p. 400-418, maio 1979.

\title{
PARENTAL AUTHORITY: FAMILY RIGHTS AND CONSTITUTIONAL PRINCIPLES
}

\begin{abstract}
The family power toward the person of the children has challenged time; it is foreseen in almost all modern legal systems and is considered one of the most important institutes of private law. This study aims to reflect upon the rights and duties of parents to their children and the changes established by Law No. 13.058/2014, with an emphasis on family relations and on constitutional principles. The methodological procedure consists of bibliographic and documentary research based on the theoretical discussion of the collected material. After the analysis, the data suggest, regarding the exercise of parental authority, that changes occurred more in the design around the institute than in the letter of law, and that one of the possible ways to make it more effective is the appreciation of the paternal and maternal authority by the family, society, and state. As to the changes introduced by the indicated Law, it was found that the prorogation of jurisdictions is just nominal, once they were foreseen in previous laws, being reintegrated in the current juridical order, or are included in other applicable laws, or were a result of joint custody. It is concluded too that the creation of ordinary law which alters another ordinary law is not always the best solution to regulate social issues. Finally, regarding the constitutional principles, it was possible to reflect on the possibility of a dialogue between family law, in general, and its family power regime, in particular.
\end{abstract}

\section{KEYWORDS}

Family. Children. Changes. Constitutional principles. Family power. 